\title{
KNOW YOUR BANKNOTES
}

\author{
S.K. Nag*
}

Banknotes or currency notes are important constituent of any economy and Indian economy is no exception. Banknotes of India are security products of high symbolic value and are considered an important national feature by this sovereign country. Currency notes of this country are an expression of stability and trust in its economic power and that explains the eternal craving for more and more of it.

\section{Genesis}

During the early days of the East India Company, several agencies and commercial houses started issuing promissory notes. General Bank of Bengal and Bihar were the early issuers of these bonds. Around 1830 some private banks namely Union Bank, Commercial Bank, Calcutta Bank, Bank of India etc. issued some small amounts of banknotes. Banknotes of Presidency banks commanded greater prestige and authority. Paper currency in India owed its birth to Sir James Wilson, the first Finance Minister in the Executive Council of the Viceroy of India, which were first released all over India by 1861. These were printed at Bank of England press.

The first currency printing press of India was commissioned on $14^{\text {th }}$ April 1928 at Nashik Road, Maharashtra. It took another 50 years to establish another Bank Note Press at Dewas, Madhya Pradesh in 1974. Two new projects at Mysore in Karnataka and Salboni in West Bengal were initiated and commissioned by Reserve Bank of India in 1996 to print banknotes in the name of its subsidiary, Bharatiya

\footnotetext{
* General Manager of Bharatiya Reserve Bank Note Mudran Limited, Bangalore.
} 
Reserve Bank Note Mudran Private Limited, to meet the increased needs of banknotes in a growing economy.

\section{Constituents of Banknotes}

The basic raw material for Indian Banknotes is watermarked paper. This is made from $100 \%$ cotton rag fibres. This gives strength and durability to paper and the linter provides brightness. The watermarked paper in our banknotes carries a three dimensional watermark of Mahatma Gandhi and it has a clear text embedded/ windowed security thread. This paper is made to specific weight and thickness and has ultra-violet fluorescing fibres in three or four colours (for various denominations) dispersed all through. It has its own unique crackle and colour.

\section{Security Features of Banknotes}

The Indian banknotes bear different overt and covert securily features incorporated in different stages of its production. Some overt features are listed below:

Rainbow effect: Gradual mixing of chosen colours.

UV Fluorescence: Central portion of the note fluoresces in ultra-violet light.

See-through design: Positive and negative of a design printed on front and back of note to register perfectly.

Bleeding design: Note design continues through the edges to another note on all four sides.

Anti-Scan lines: These make the banknotes photocopying, scanner and scanning proof.

Relief effect: Tactile image through intaglio printing (for higher denomination notes Rs. 20 and above denomination notes).

Fine engraving: To give majestic aestheticism.

Latent image: Concealed image visible only at acute angles.

Micro-lettering: Fine small letters denoting 'RBI' and the denomination.

Portrait: Hand engraved portrait of Mahatma Gandhi.

Numbering: Unique ultra-violet fluorescent numbers at top right and bottom left portions. The numbering in Rs. 5 Bank note is however in bottom right portion. 
Colour shift ink: Central numeral of Rs. 500/- and Rs. 1000/- in dual colour ink. The central numeral number in these two denominations changes from Green to Blue colour when the note is tilted by 30 degrees. This is an additional security feature in these bank notes.

The above overt security features in combination with other covert features of design; materials and processes add further weightage to this sovereign product. These also act as effective anti-counterfeiting features.

\section{Challenges by Counterfeiters}

If the rationale for users' behaviour when they prefer cash, is their sense of confidence in it, then where does this confidence come from? It flows from their ready and sustained knowledge of how much cash they have, the quality images they identify with and its integrity. If flows from banknote to individual by look and feel. The look and feel are created by users' visual response to the output of creative design process and their tactile response to the combination of paper quality and printing processes. Counterfeit or fake notes fail the user in all these parameters. However counterfeiters still persist, but with little or one time success and their product dies a premature death. Computers with scanners and colour photocopiers pose a threat, though in a small way, in generating counterfeit notes.

\section{Design of Banknotes}

Design elements of banknotes are uniquely generated using sophisticated tools. These include guilloches, filigrees, rosettes, scrolls, patterns, textures include portraits, typography, colour, hand engraved elements and finish. Their creation is specially measured, controlled and monitored for their various parameters like thickness, space, colour density, frequency, stability etc. during creation and reproduction. All elements in their appropriate assemblage will give an aesthetically pleasing and majestically authoritative banknote.

\section{Typical Case Study of Existing Security Features in Rs. 100 Banknote}

It is interesting to know that Rs. 5 and Rs. 10 denomination notes are devoid of intaglio printing (raised printing or relief). Presently, the security thread from Rs. 5 to Rs. 50 is fully embedded, which fluoresces in blue colour under ultra-violet rays. Rs. 100 and above denomination notes have windowed security thread. The security thread in Rs. 1,000, however, differs from that of Rs. 100 and Rs. 500. The windowed thread in Rs. 1,000 gives rainbow effect in three colours when seen in UV rays. 
Rs. 500 and Rs. 1000 being high-value notes, have additional security features in the form of Optically Variable Ink (OVI). in the Central Numeral of these notes. The colour of the ink varies from Green to Blue when tilted and seen with naked eyes.

Having discussed certain security features of banknotes in the earlier Para, a detailed in built security feature in Rs. 100 banknote are discussed herewith by way of illustrations.
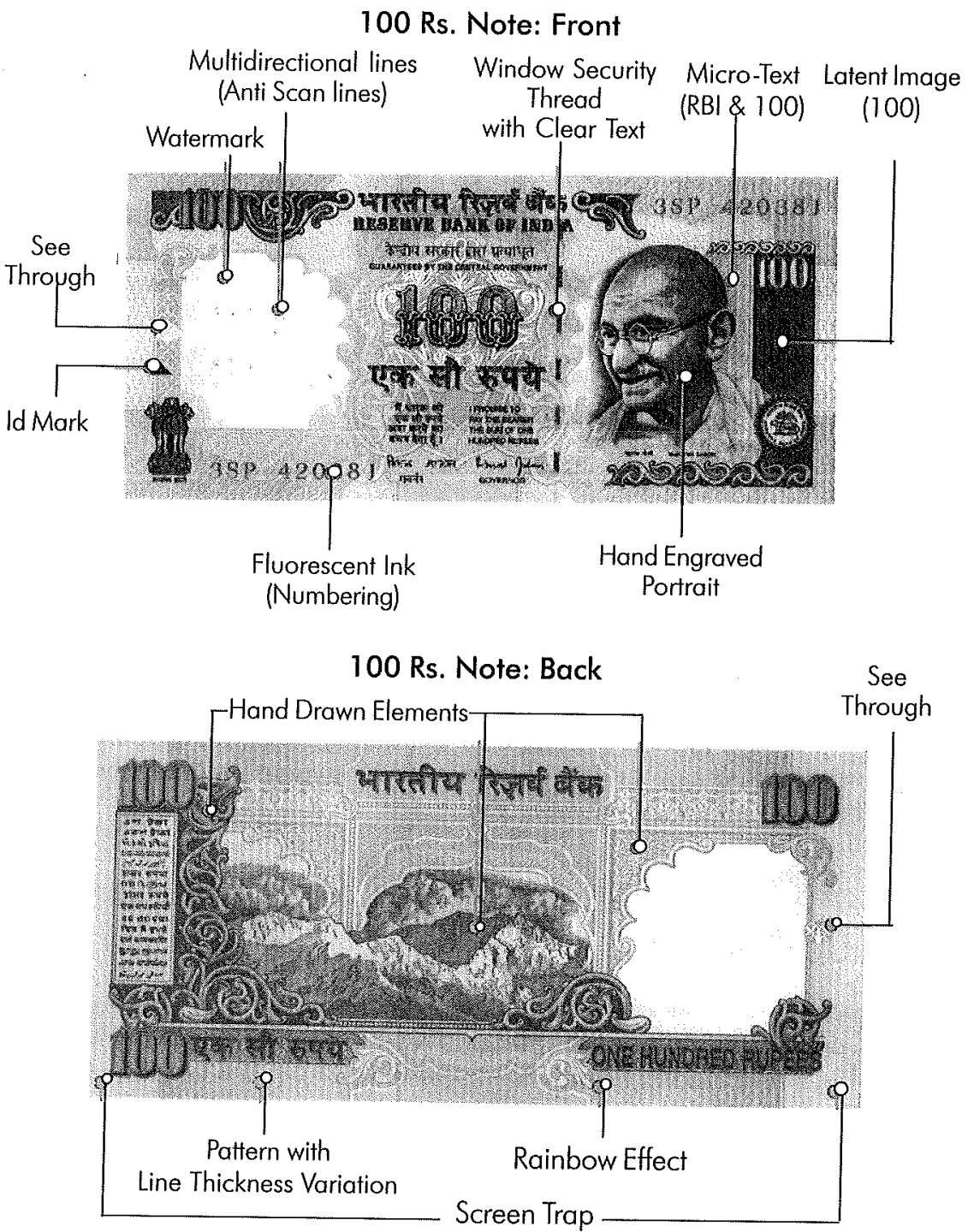


\section{Watermark}

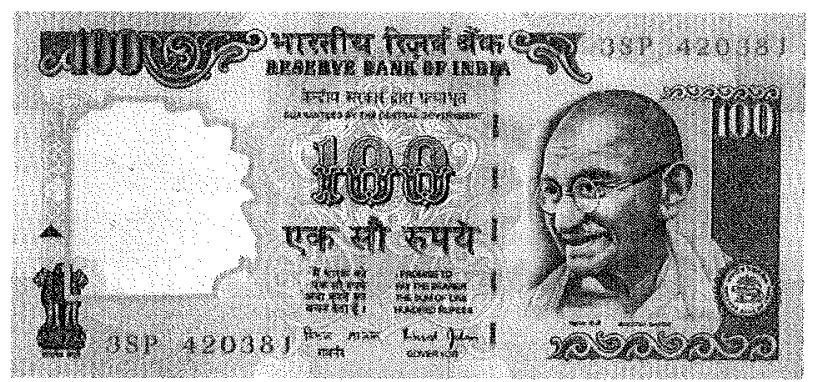

The watermark in new 100 Rupee Note depicts Mahatma Gandhi. Visible from both front and back in transmitted light.

Cannot be replicated using scanning or photocopy equipments.

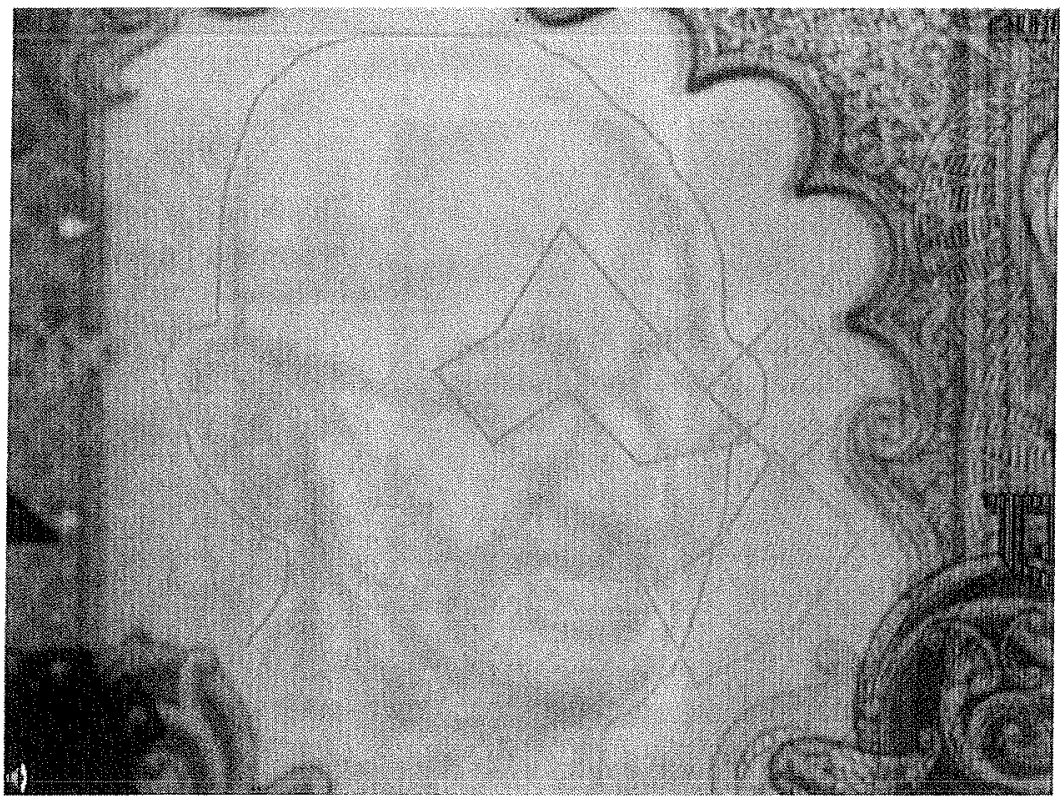



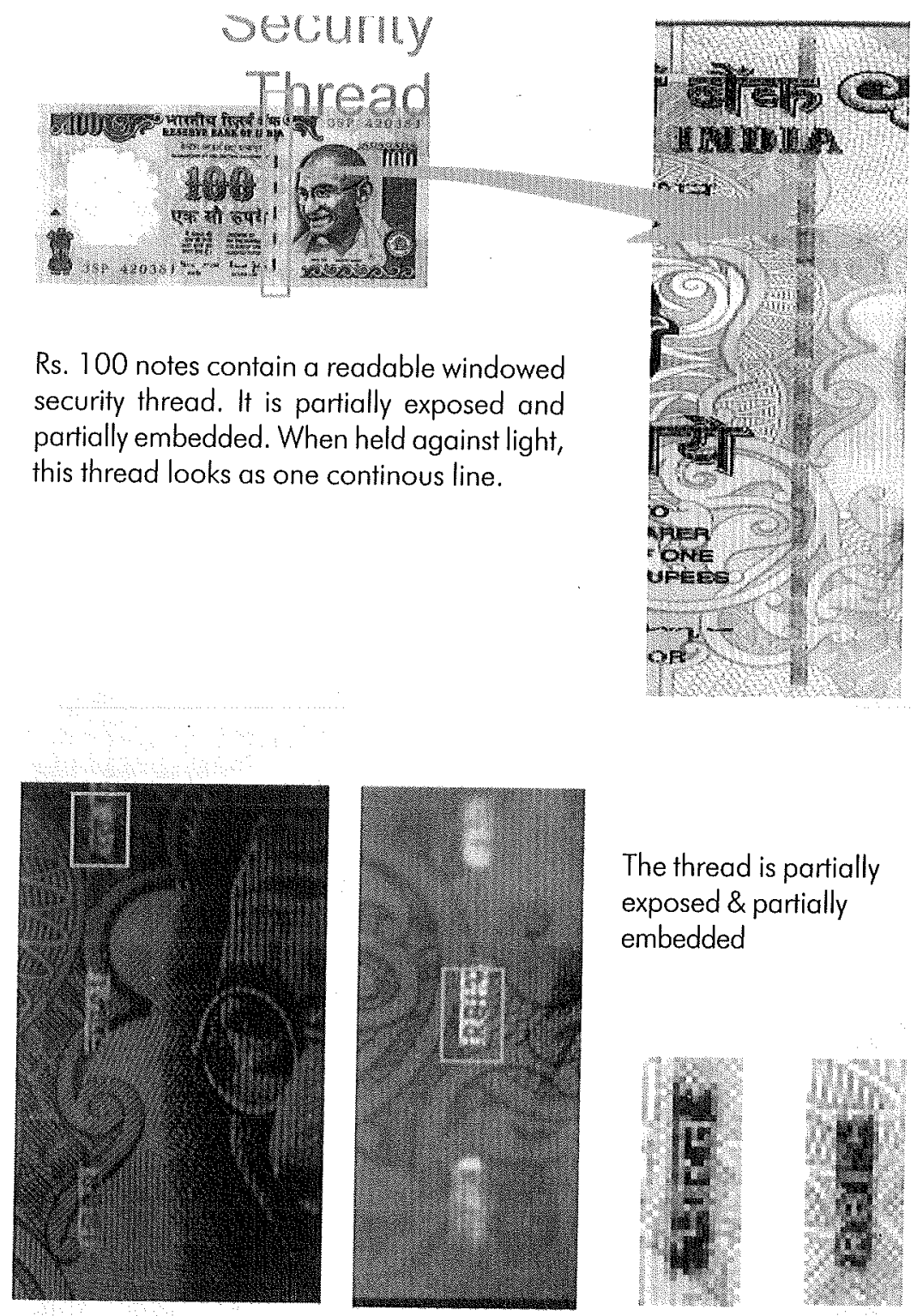

The thread is partially exposed \& partially embedded
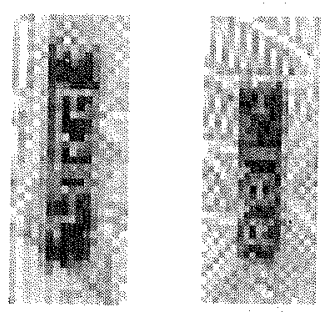

Rs. 100/-contain a readable windowed clear text: Security thread. It contains the words "Bharath" in the Devanagari script and "RBI" appearing alternately. 


\section{Intaglio Printing}
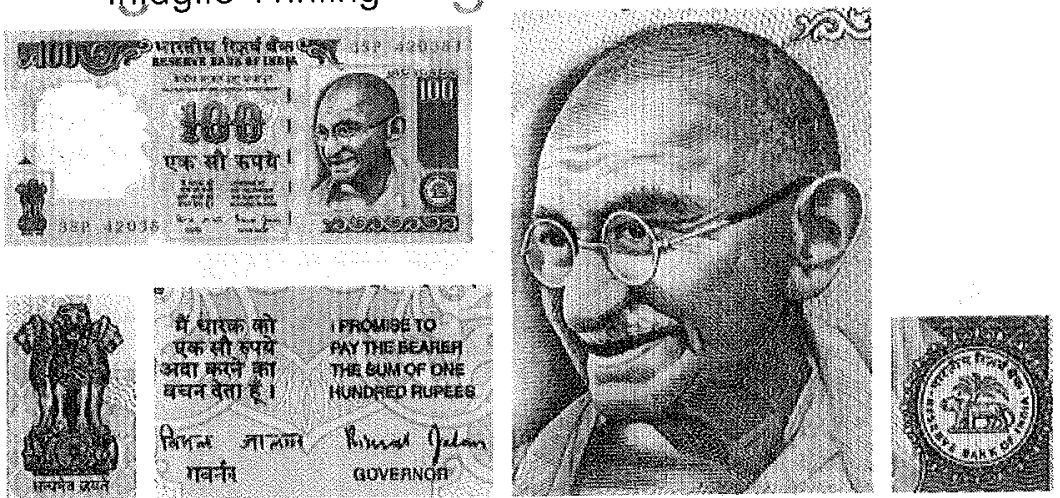

The portrait of Mahatma Gandhi, Reserve Bank Seal, guarantee and promise clause, Ashoka pillar emblems on the left, RBI Governor's signature are printed in intaglio i.e., in raised prints.

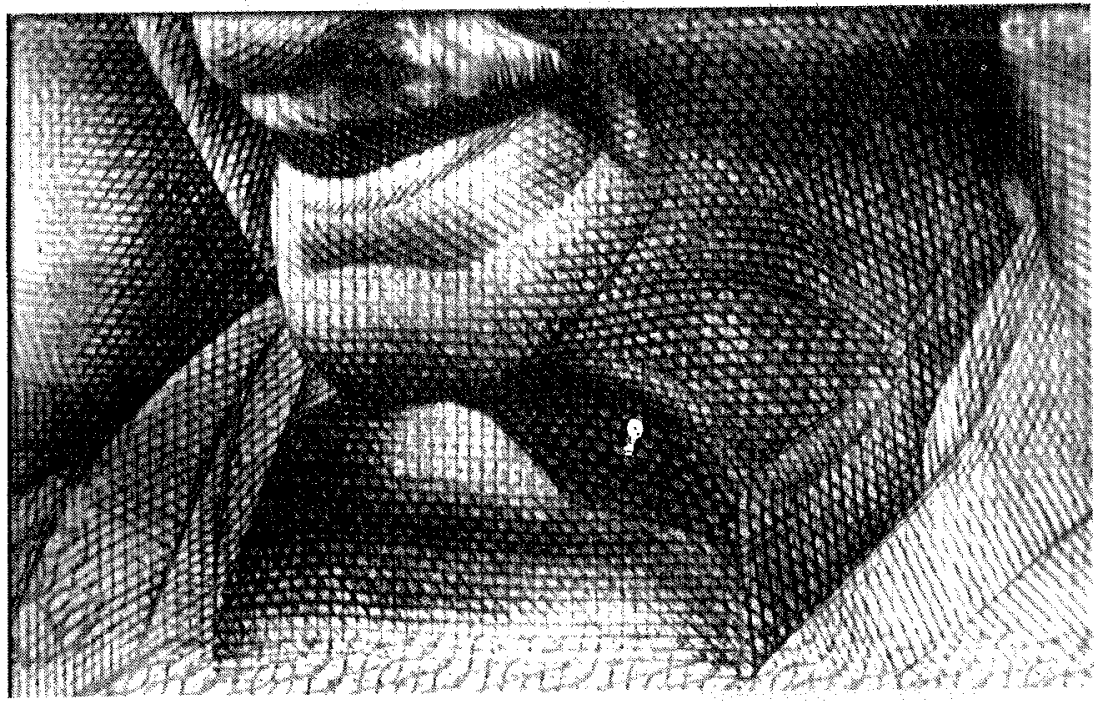

- It appears life like and it stands out distinctly.

- Deep engravings \& minute details of the portrait adds to the security of bank notes against counterfeiting. 
- A counterfeit portrait is usually lifeless \& flat and the details merge into the background unlike this portrait.
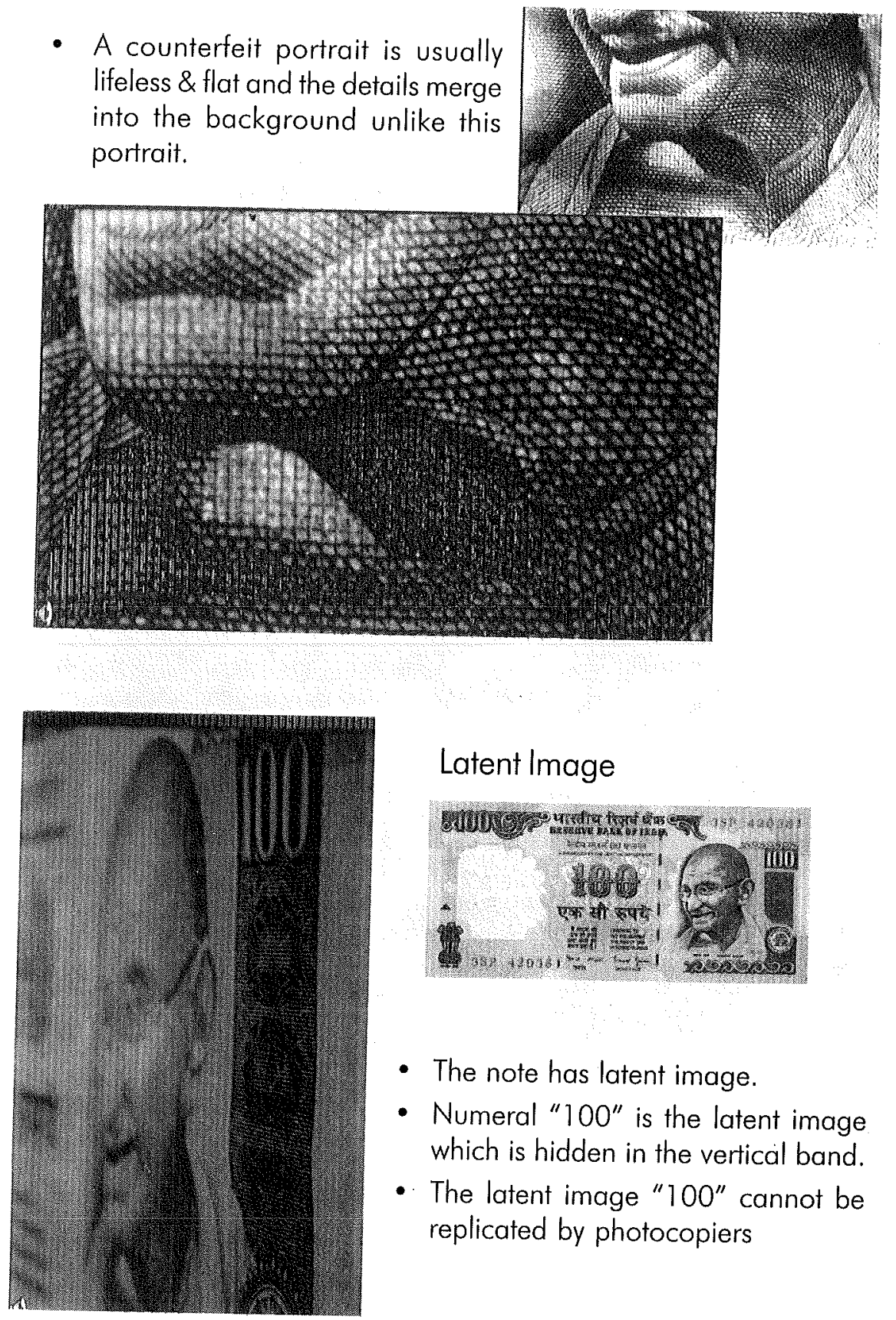

\section{Latent Image}

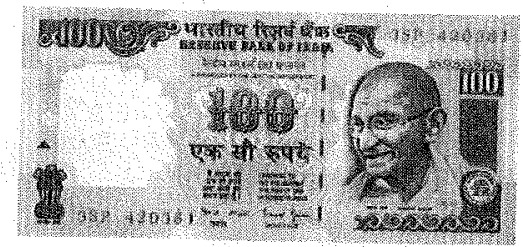

- The note has latent image.

- Numeral "100" is the latent image which is hidden in the vertical band.

- The latent image "100" cannot be replicated by photocopiers 

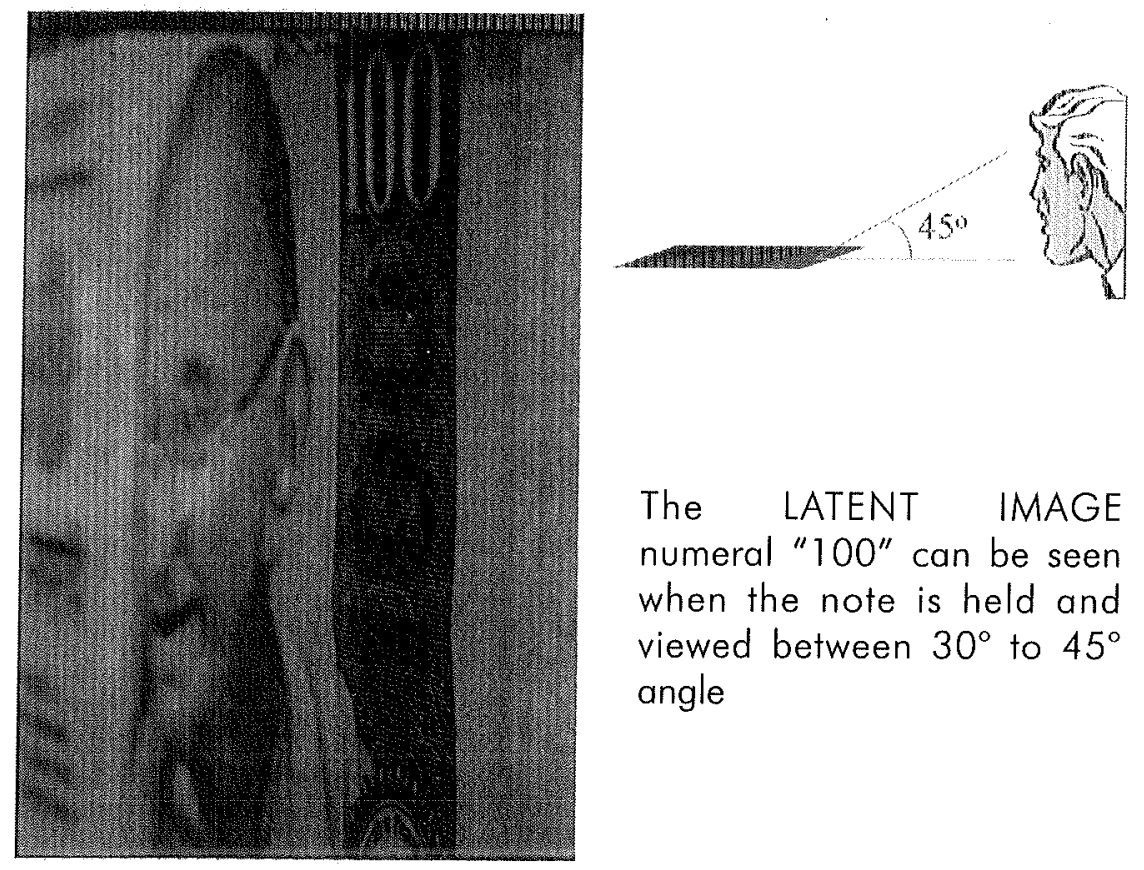

The LATENT IMAGE numeral "100" can be seen when the note is held and viewed between $30^{\circ}$ to $45^{\circ}$ angle
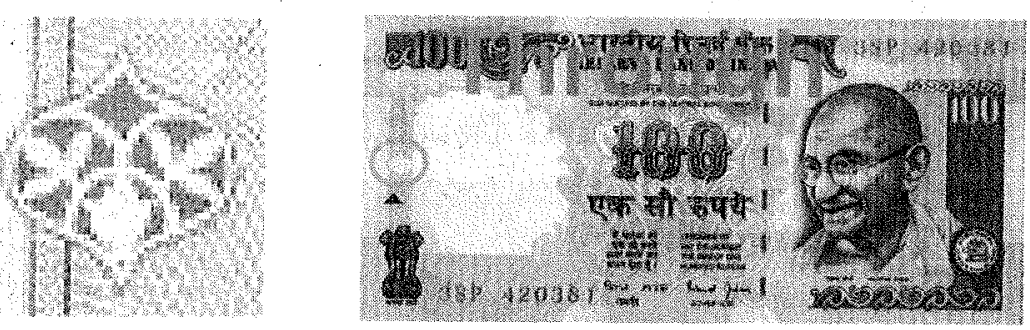

See-through is a flower like design that renders additional security to our notes.

It is in the left side \& above identification mark.

The printing requires perfect registration between front and back.

Replication is difficult on commercial machines. 
The printing of both front and back is done in a single pass and designs are printed in front \& back with perfect registration which renders the note a "see-through" effect.

\section{Front Design}

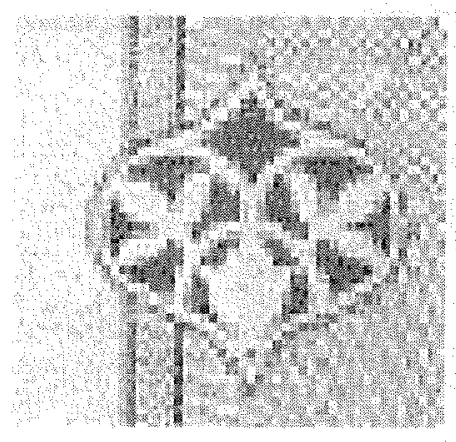

The printing of both front and back is done in a single pass and designs are printed in front $\&$ back with perfect registration which renders the note a "see-through" effect.

\section{Back Design}

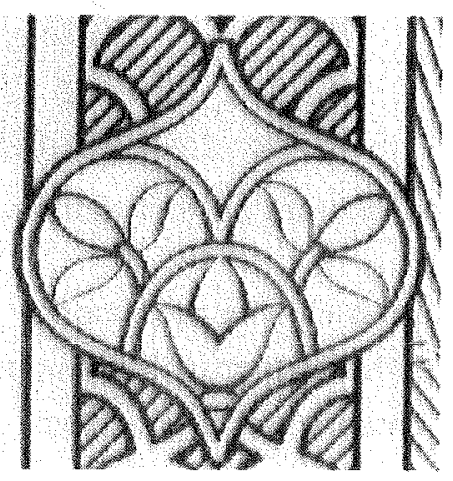


The printing of both front and back is done in a single pass and designs are printed in front $\&$ back with perfect registration which renders the note a "see-through" effect.

Front Design

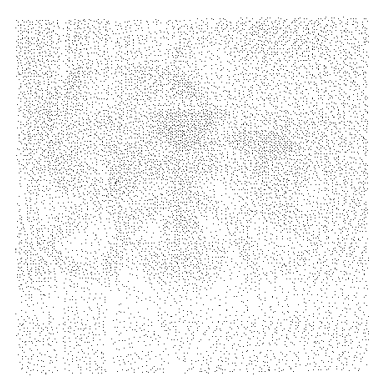

See-Through Design

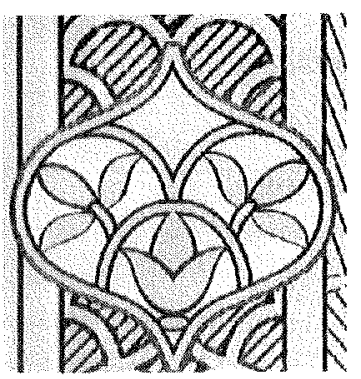

Back Design

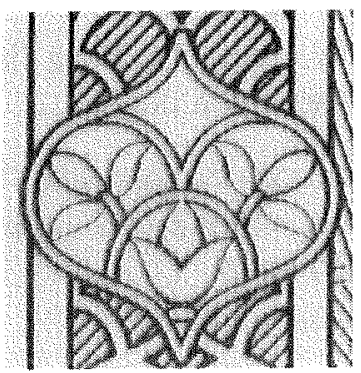

\section{Identification Mark}
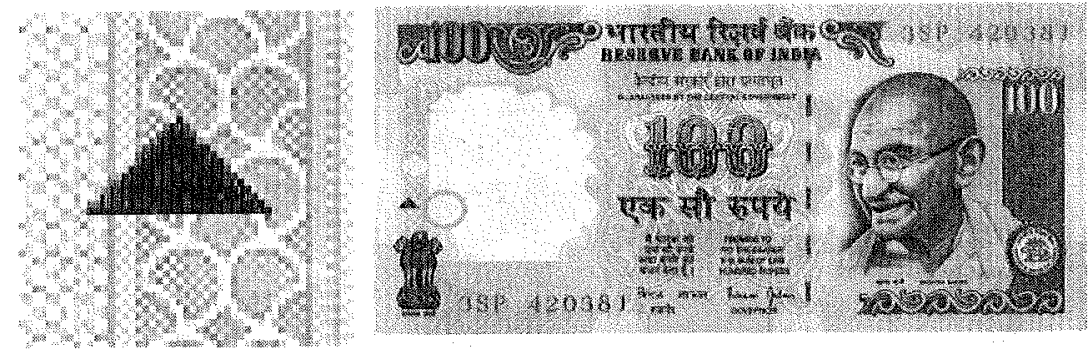

An identification mark has been introduced in the note for visually impaired people.

This mark is in intaglio printing and it is in different geometrical shapes for various denomination.

For Rs. 100-denomination, we have triangle ' $\triangle$ ' as the identification mark. 


\section{Fluorescence}

Number panels of the notes are printed in fluorescent ink

The notes also have fluorescent fibres in the paper.

Both can be seen when the notes are exposed to ultra-violet (UV) lamp.

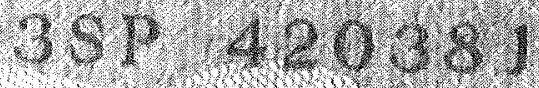

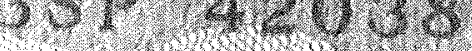
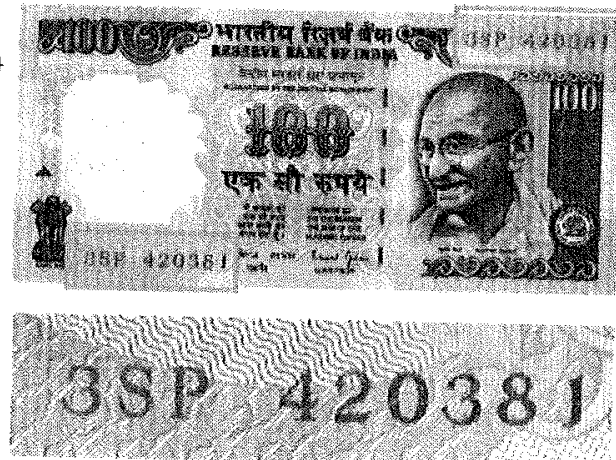

\section{Rs. 100 - Back}

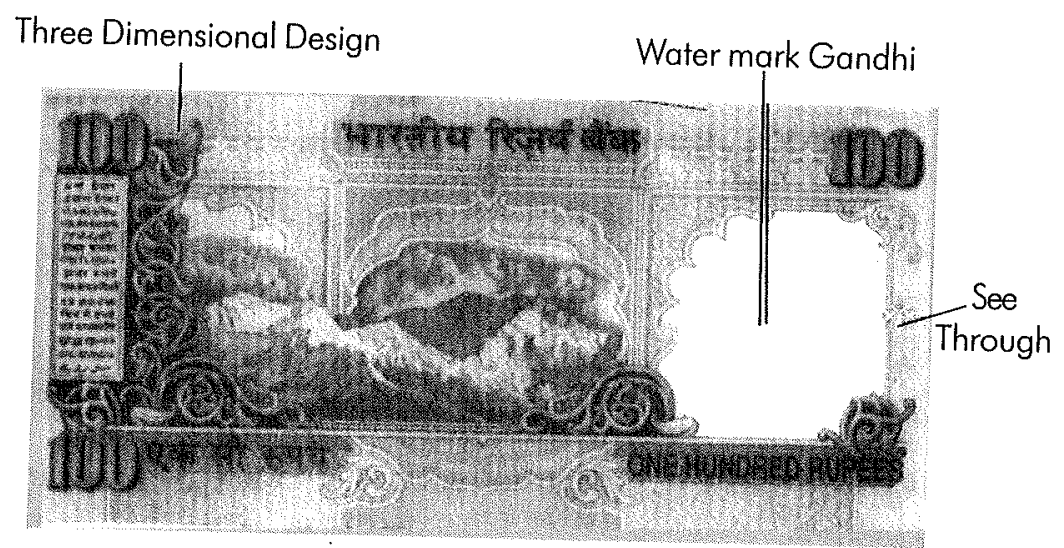




\section{Rs. 500/- Denomination Bank Note}

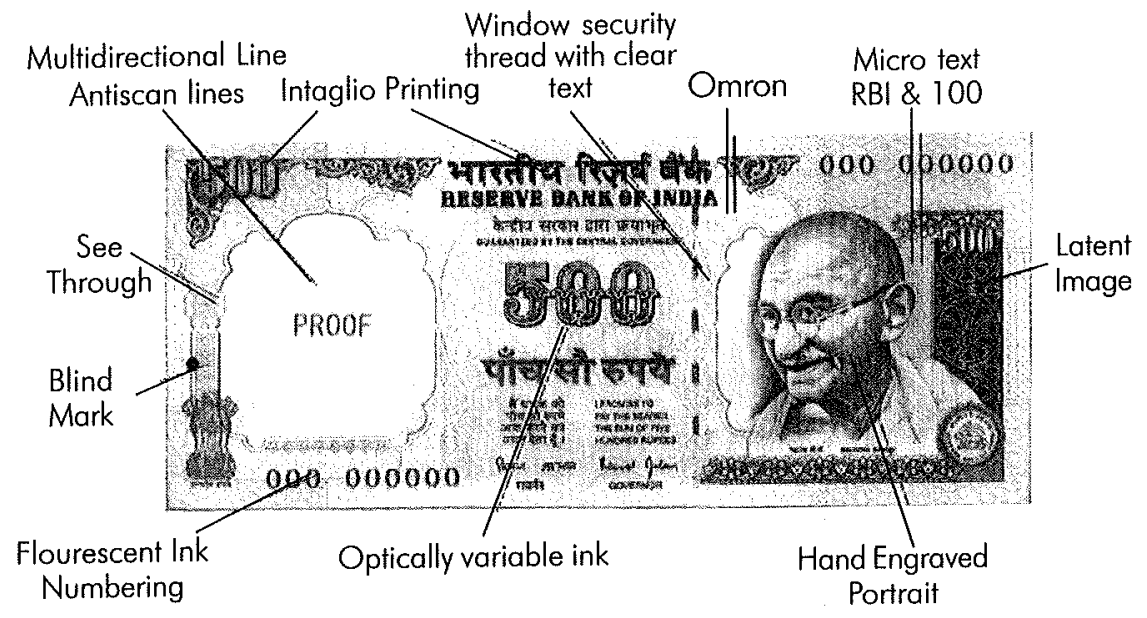

\section{$: 2:$}

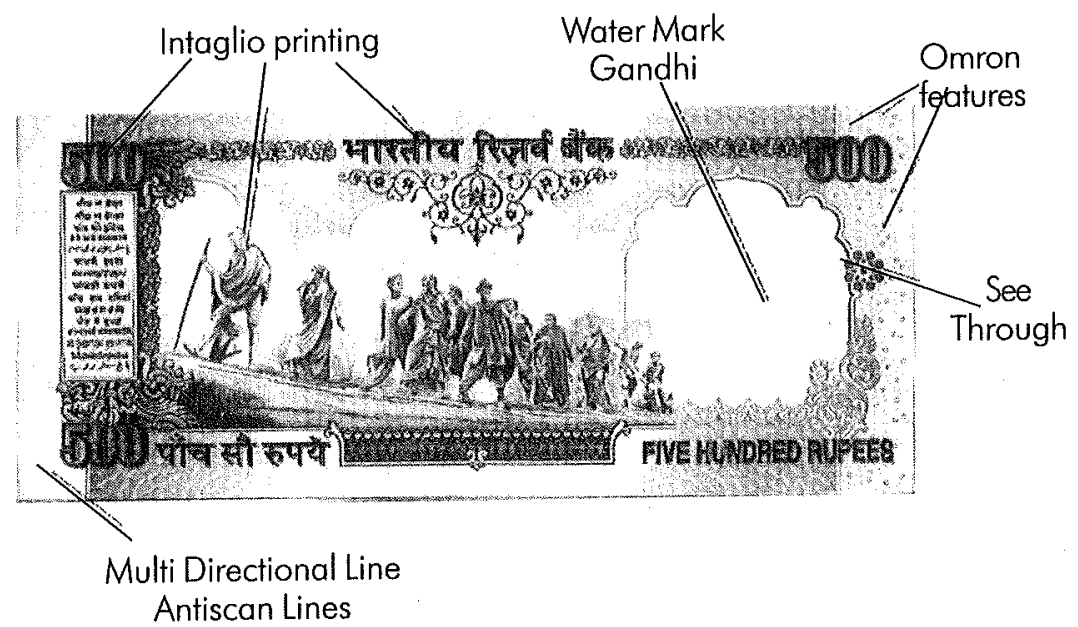

